\title{
Fitopatologia Brasileira goes international
}

The journal Fitopatologia Brasileira was founded by the Brazilian Phytopathological Society in 1974 and began its life with the publication of the first volume in 1976. Since then, the journal has published scientific articles describing original research in the field of Plant Pathology. The publications contribute to the development of agribusiness, covering all strategies in plant disease control with the aim of guaranteeing high productivity, quality and safety for agricultural products and their derivates.

Today, Brazil occupies a leading position in terms of tropical and subtropical agriculture, with activities maintaining a high level of technology and productivity and a strong tendency to expand, especially with regard to export products. There is a high demand for generation and dissemination of knowledge on all the fast-developing aspects of plant protection and production following high quality standards.

This tendency has attracted the attention of the international community and can be interpreted as an incentive to fill a gap by producing a periodical that publishes results in the field of plant protection in tropical and subtropical agriculture. Brazil has shown a natural calling and accumulated competence to act as a leader in expanding the knowledge base and in the generation of agricultural technology, including the field of plant protection.

In accordance with these prospects, the Brazilian Phytopathological Society decided at its Assembly during the 2006 Annual Meeting in Salvador, Bahia, to publish the official journal, from 2008 onwards, under the name Tropical Plant Pathology.

This decision is the result of a broad discussion about what would be the right strategy to improve quality and exposure for the international community of a journal that has been published for 36 years. Citing the Editorial of another young, but high quality journal, it is possible to describe our main objective in just a few words: "Fitopatologia Brasileira goes international". Changing the name, along with an international publicity campaign, should boost the visibility of the journal and, as a consequence, lead to much greater impact.

After changing the name to Tropical Plant Pathology, our aim for the years 2008-2009 is the adoption of an electronic submission and evaluation process online, following the philosophy of an Open Access Journal, with the support of SciELO - Scientific Electronic Library Online. We would like to take the opportunity to express our appreciation to the heads and the team of SciELO, which has offered several Brazilian journals the real opportunity to go international, overcoming the dichotomy between "Brazilian" and "International".

The number of publications in English should increase. In this context, the participation of referees and Editors from other countries will also naturally increase. Following recommendations in order to adopt international standards, it is still necessary to diversify contributions from authors, referees and Editors.

Although Tropical Plant Pathology is an official publication of the Brazilian Phytopathological Society, it is open to members and non-members of the Society, professionals from all over the world who would like to submit papers and share their experience. Original Research Articles and Short Communications which report results of original research in all fields of Plant Pathology are accepted. Review articles are also welcome, as are reports on new trends or methods in the field of Plant Pathology. 